\title{
WOMEN SELF SECURITY SYSTEM USING AWS AND IOT
}

\author{
M.Sairam, D.Nikhita, G.Rajesh, P.Shyam Sandesh \\ Department of Electronics \& Communication Engineering \\ Godavari Institute of Engineering and Technology (Autonomous Institution) \\ NH-16, Chaitanya Knowledge City, Rajahmahendravaram, A.P., INDIA-533294. \\ J. Mahesh Kumar, Assistant Professor \\ Department of Electronics \& Communication Engineering \\ Godavari Institute of Engineering and Technology (Autonomous Institution) \\ NH-16, Chaitanya Knowledge City, Rajahmahendravaram, A.P., INDIA-533294.
}

\begin{abstract}
The main aim of the proposed work is to provide security for woman. In case of emergency situations woman will press an emergency, button which will activates the GPS for location tracking and a SMS is sent to the police and family members of woman along with time. This proposal document describes a quick responding, cost protection system for an individual and especially for women using which a woman in distress can call for help just with the press of a button on this smart gadget. Self-defense system for women safety is like a Smart Watch for Women. It has the ability to help women with technologies that are embedded into a compact device. The women carrying this device in a handbag in case of any harassment or when she finds that someone is going to harass, she presses a switch/band that is allocated for her after fabrication, then the band will activate and the location information is sent as SMS alert to a few predefined emergency numbers And soon help is on its way! The system will consist of embedded hardware and software code signed for this dedicated application. The system allows for knowing exact location of the individual, by providing the instant location of the distressed victim to the police so that the incident could be prevented and the culprit apprehended. In case if the caretaker wants to know the present location of the lady, he/she can do so by sending a SMS to the SIM number of the lady which contains a secret password. Then this system responds to such request by sending back a SMS containing location information in terms of Latitude and Longitude. This proposed work is done using AWS and IOT.
\end{abstract}

Keywords: SMS, SIM, Global Positioning System, $A W S$, and IOT.

\section{INTRODUCTION}

Now a day's attacks on woman is increasing day by day and in the case of where she can't take a mobile and dialup to police or other family members, our proposal will be very much helpful in such cases in not only informing about attacks but also in giving the exact location of the women to nearby police station for necessary action. In today's world, women safety has become a major issue as they can't step out of their house at any given time due to physical/sexual abuse and a fear of violence. Even in the 21 st century where the technology is rapidly growing and new gadgets were developed but still women and girls are facing problems. Even today in India, women cannot move at night in many places and even at day time crowded places hundreds and thousands of incidents of physical/sexual abuse happens to women every day. [1].Among other crimes, rape is the fastest growing crime in the country today. Women will be provided with equipment which is not visible to others the equipment consists of GPS (Global Positioning System) module by which we can get the geographical location and these location values are displayed on the LCD (Liquid Crystal Display). In the case of any emergency conditions she can press a button once then the location information will be tracked and sent to police and family members so that she will be protected in proper time. [3]. 


\section{LITERATURE SURVEY}

2.1.Jivi 2010: This is a feature of Jivi mobile with a fully dedicated SOS button aimed at women. In case of any emergency or unfortunate times, user needs to long press the SOS button and the phone starts calling 5 pre-stored numbers one after the other. In case any of the numbers is busy or does not take the call, a SMS is sent to the number. After this, the phone automatically dials other numbers on the predefined list - thereby ensuring immediate help.

2.2.VithU app: It is mobile application used in smart phone in which, when power button is pressed two times helping message regarding the location of women(user) will be sent to already stored contacts. Sent information (location) is updated after every two.[5].

2.3 "Technological Interventions to Detect, Communicate and Prevent Sexual Assault" by manisha mohan, 2015.This is the type of technology she implemented in order to protect the women from the sexual assault. where she got faced this problem forcibly in his career in order to overcome this problem she developed the Aluminum strip attached to the safety ware of woman, when any of the person who tries to do the sexual forcibly it detect the touch and send the information to the regarding family members and the respective near police station. [4].

\section{SYSTEM SETUP}

(A)Hardware Components:

- Arduino Uno

- Logic Level Converter

- ESP8266

- GPS

- PIR sensor

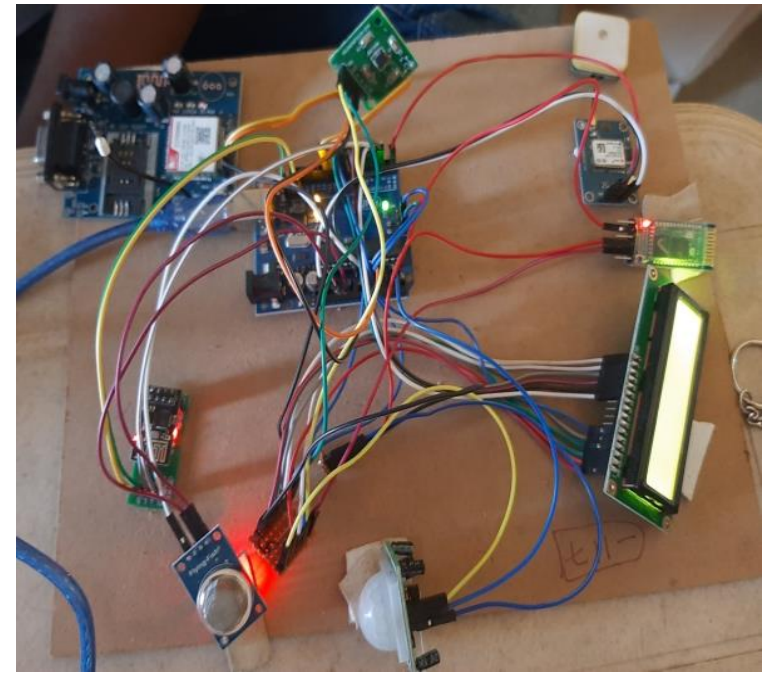

Figure1.System setup.

\section{A1. Arduino Uno:}

Arduino is

an open-source hardware and software company, project and user community that designs and manufactures in the single-board microcontrollers and microcontroller kits for building digital devices and interactive objects that can sense and control both physically and digitally.

"Uno" means one in Italian and was chosen to mark the release of Arduino Software (IDE). The Uno board and version 1.0 of Arduino Software (IDE) were the reference versions of Arduino, now evolved to newer releases. The Uno board is the first in a series of USB Arduino boards, and the reference model for the Arduino platform. The ATmega328 on the Arduino Uno comes pre-programmed with a boot loader that lows uploading new code to it without the use of an external hardware programmer. It communicates using the original STK500 protocol. The Uno also differs from all preceding boards in that it does not use the FTDI USB-to-serial driver chip. Instead, it uses the Atmega16U2 (Atmega8U2 up to version R2) programmed as a USB-to-serial converter.[5].

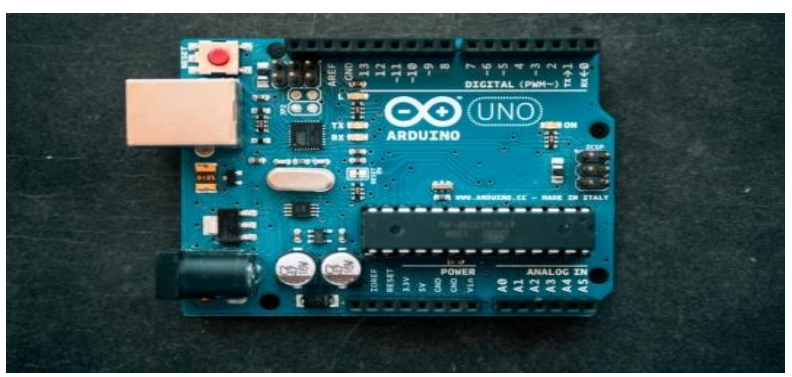

Figure2. Arduino Uno. 


\section{A2. Logic Level Converter:}

A logic-level

converter in digital electronics, also called a level shifter is a circuit used to translate signals from one logic level or voltage domain to another, allowing compatibility between ICs with different voltage requirements, such as TTL and CMOS. Many modern full featured systems use level shifters to bridge domains between low-power application processors running at $1.8 \mathrm{~V}$ and other system functions like sensors or other Analog intensive applications running at 3.3 or $5 \mathrm{~V}$.

\section{A3. ESP8266:}

The ESP8266 Arduino compatible module is a lowcost Wi-Fi chip with full TCP/IP capability, and the amazing thing is that this little board has a MCU (Micro Controller Unit) integrated which gives the possibility to control I/O digital pins via simple and almost pseudo-code like programming language. This device is produced by Shanghai-based Chinese manufacturer, Espress if Systems.[4].

This chip was first time seen in August 2014, in ESP-01 version module, made by AIThinker, a third-party manufacturer. This little module allows the MCU to connect to Wi-Fi network and create simple TCP/IP connections[5]..

\section{A4. GPS (Global Positing System):}

Global Positioning System is vast, expensive and involves a lot of technical ingenuity, but the fundamental concepts at work are quite simple and intuitive.

When people talk about "a GPS," they usually mean a GPS receiver. The Global Positioning System (GPS) is actually a constellation of 27 Earthorbiting satellites (24 in operation and three extras in case one fails). The U.S. military developed and implemented this satellite network as a military navigation system, but soon opened it up to everybody else.

Each of these 3,000- to 4,000-pound solar-powered satellites circles the globe at about 12,000 miles $(19,300 \mathrm{~km})$, making two complete rotations every day. The orbits are arranged so that at any-time, anywhere on Earth, there are at least four satellites "visible" in the sky.

A GPS receiver's job is to locate four or more of these satellites, figure out the distance to each, and use this information to deduce its own location. This operation is based on a simple mathematical principle called trilateration. Trilateration in three-dimensional space can be a little tricky, so we'll start with an explanation of simple two-dimensional trilateration.

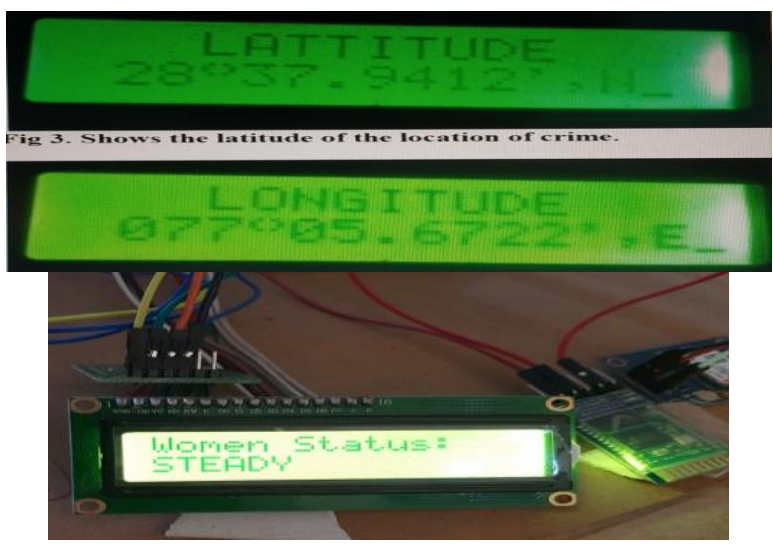

Figure3.LCD, showing status.

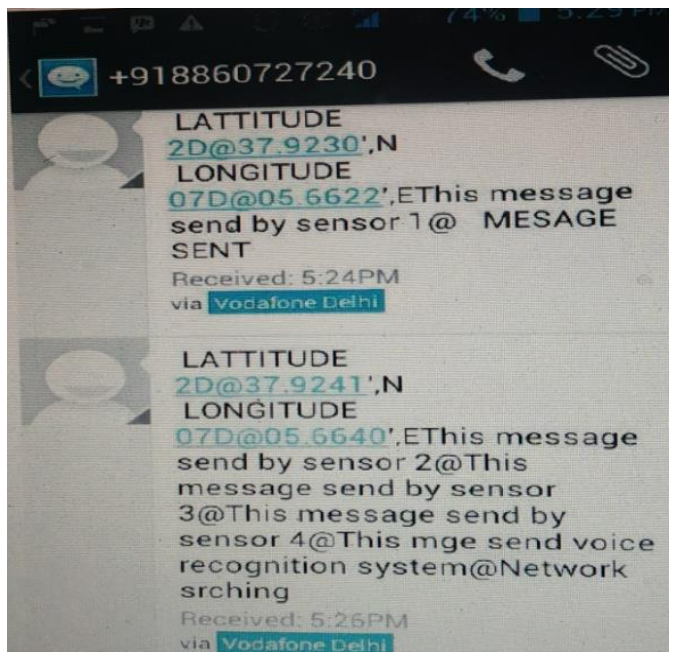

Figure4.Display of Tracking.

\section{A5.PIR Sensor:}

PIR sensors allow you to sense motion, almost always used to detect whether a human has moved in or out of the sensors range. They are small, inexpensive, low-power, easy to use and don't wear out. For that reason, they are commonly found in appliances and gadgets used in homes or businesses. They are often referred to as PIR, "Passive Infrared", "Piezoelectric", or "IR motion" sensors.[5]. 


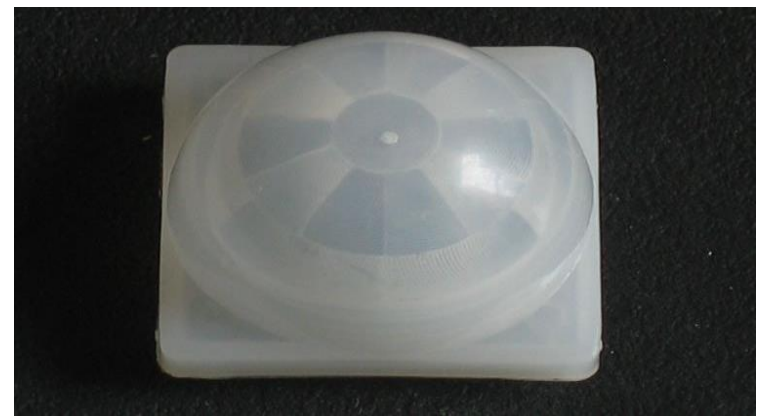

Figure5.PIR sensor.

\section{(B)Software Components:}

- Amazon web service

\section{B1. Amazon web service:}

Amazon Web Services (AWS) is a subsidiary of Amazon that provides on demand cloud computing platforms to individuals, companies and governments, on a metered pay-as-you-go basis. In aggregate, these cloud computing web services provide a set of primitive, abstract technical infrastructure and distributed computing building blocks and tools. One of these services is Amazon Elastic Compute Cloud, which allows users to have at their disposal a virtual cluster of computers, available all the time, through the Internet. AWS's version of virtual computers emulate most of the attributes of a real computer including hardware (CPU(s) \& GPU(s) for processing, local/RAM memory, hard-disk/SSD storage); a choice of operating systems; networking; and pre-loaded application software such as web servers, databases, CRM,

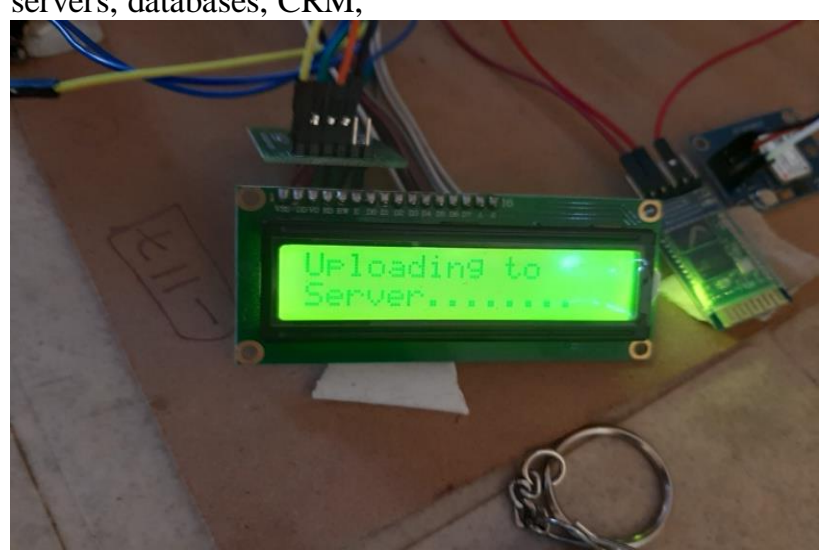

Figure6.Display showing connecting to AWS.

3.B1.1.GSM: (Global system for mobile communication) Is the technology is the underpins most of the worlds mobile phones networks. The GSM platform is hugely successful wireless technology and an unprecedented story of global achievement and cooperation. GSM is an open digital cellular technology used for transmitting mobile voice and data services.GSM operates in range of $900 \mathrm{MHz}$ and $1.8 \mathrm{kbps}$, allowing the transmission of basic data services such as sms.[5].

\section{METHODOLOGY}

\section{(A). MEASURED PARAMETERS:}

\section{A1.PIR SENSOR:}

PIR sensors allow you to sense motion, almost always used to detect whether a human has moved in or out of the sensors range. They are small, inexpensive, low-power, easy to use and don't wear out. For that reason, they are commonly found in appliances and gadgets used in homes or businesses. They are often referred to as PIR, "Passive Infrared", "Pyroelectric", or "IR motion" sensors.

\section{A2.MEMS SENSOR:}

Micro-Electro-Mechanical Systems, or MEMS, is a technology that in its most general form can be defined as miniaturized mechanical and electromechanical elements (i.e., devices and structures) that are made using the techniques of micro fabrication. The critical physical dimensions of MEMS devices can vary from well below one micron on the lower end of the dimensional spectrum, all the way to several millimeters. Likewise, the types of MEMS devices can vary from relatively simple structures having no moving elements, to extremely complex electromechanical systems with multiple moving elements under the control of integrated microelectronics. The one main criterion of MEMS is that at least some elements are having some sort of mechanical functionality whether or not these elements can move. The term used to define MEMS varies in different parts of the world. In the United States, they are predominantly called MEMS, while in some other parts of the world they are called "Microsystems Technology" or "micro machined devices".[2].

\section{A3. MQ2 SENSOR:}

The Grove - Gas Sensor (MQ2) module is useful for gas leakage detection is suitable for detecting $\mathrm{H} 2$, LPG, CH4, CO, Alcohol, Smoke or Propane. Due to its high sensitivity and fast response time, the measurement can be taken as soon as possible. The sensitivity of the sensor can be adjusted by the potentiometer. computing platforms to individuals, companies, and governments, on a metered pay-asyou-go basis. In aggregate, these cloud computing web services provide a set of primitive, 
abstract technical infrastructure and distributed computing building blocks and tools. One of these services is Amazon Elastic Compute Cloud, which allows users to have at their disposal a virtual cluster of computers, available all the time, through the Internet. AWS's version of virtual computers emulate most of the attributes of a real computer including hardware (CPU(s) \& GPU(s) for processing, local/RAM, hard-disk/SSD storage); a choice of operating systems; networking; and pre-loaded application software such as web servers, databases, CRM, etc.[5].

\section{(B)DISPLAY HARDWARE:}

It has 16 pins and the first one from left to right is the Ground pin. The second pin is the VCC which we connect the 5 volts pin on the Arduino Board. Next is the Vo pin on which we can attach a potentiometer for controlling the contrast of the display. Next, The RS pin or register select pin is used for selecting whether we will send commands or data to the LCD. For example if the RS pin is set on low state or zero volts, then we are sending commands to the LCD. We use this register to insert a command into the LCD. These commands can be things like telling the LCD to clear the screen, set the cursor, move to line 1 , move to character 1 , etc. Here's the table of all the commands that you can send to the lcd.[1\&3].

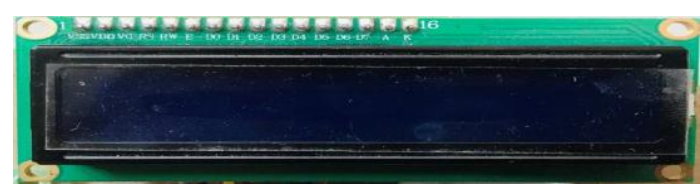

Figure7.LCD.

\section{(C) AURDINO PROGRAM:}

The proposed Embedded device system is for checking women security and provide an exact tracking location of a women. the proposed model consists of 4 tires ..,

1.Tier1 provides an information regarding the motion of a women through the PIR sensor, which consists of a lens inside the sensor. It detects the any of the victim near by the sensor it detects the motion and sends the SMS.

2.Tier2 provides the incident of a victim direction whether the frontend side or backend side through the MEMS sensor. Whenever the victim overcomes the threshold limit of distance towards women then it activates and sends the SMS.
3.Tier3 gives the information regarding the information of the alcoholic person/ not through the GAS sensor.

4.Tier4 it uploads the information to the server through the AWS server so that we can also get the information of a women.

\subsection{IOT:}

\section{IMPLEMENTATION}

The final result of a module regarding the women self safety as shown below, the women exact tracking through AWS software.

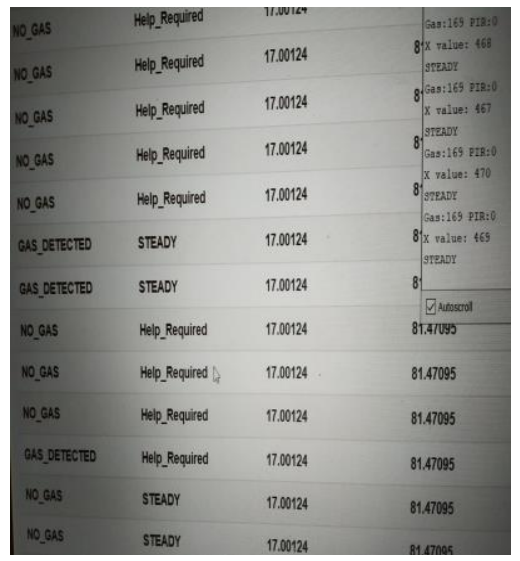

Figure8.Display through AWS and IOT.

\section{RESULTS}

In this portion the result of the project is depicted with the help of snapshots. The main data analysis tool Amazon Web Services consists of various type of information, we can easily find out different types analysis values like women position whether she is in safety/ help-required, sending SMS, uploading server.[2].

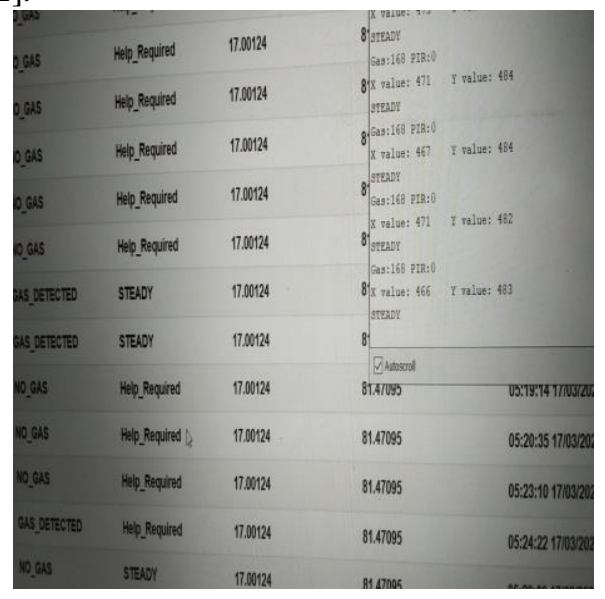


Figure9. Represents the women exact safety position whether steady / help required.

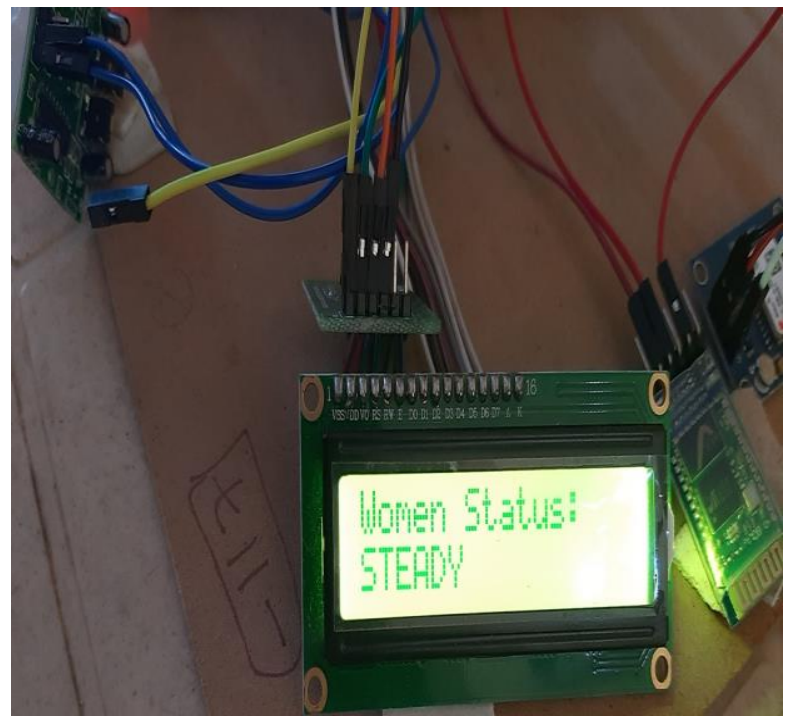

Figure10. It represents that women is in steady/ safe mode.

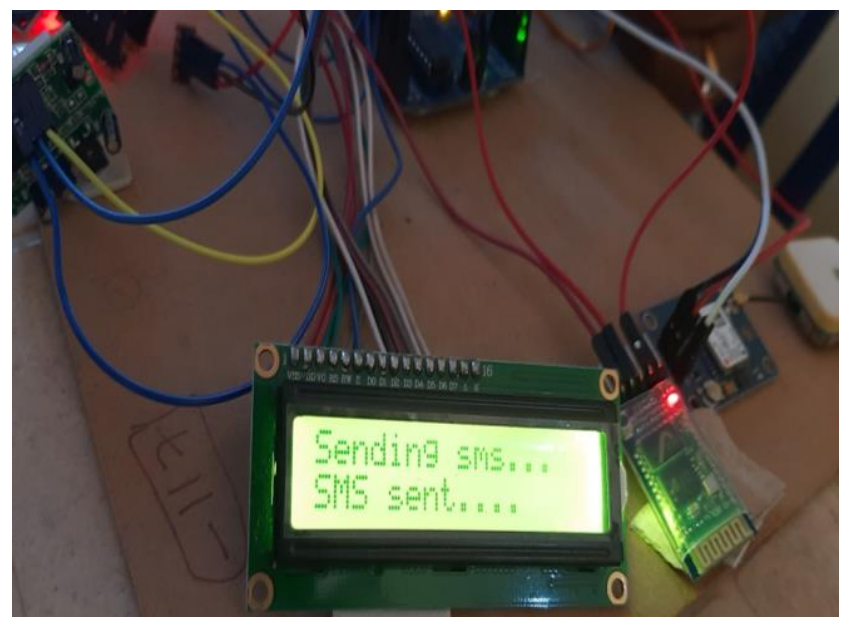

Figure11. It shows that when the woman is in the danger mode any sensor detects the women tracking location and sends the SMS.

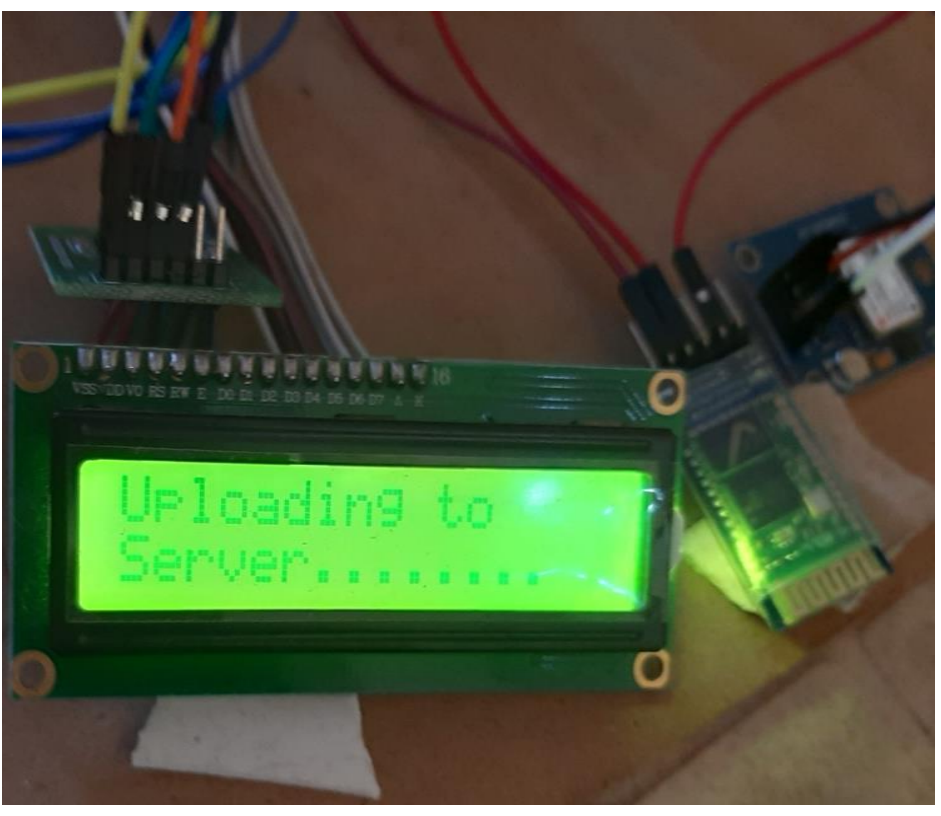

Figure12. It shows the regarding position, location, time is uploading top server online.

\section{CONCLUSION}

This paper reviewed the emergency response which is helpful for women in the incidents of crime. The main objective is to develop the low-cost system which can store the data of the members in the particular locality and provide immediate alert in case of crime against women. This provides women security. Being safe and secure is the demand of the day. Our effort behind this project is to design and fabricate a gadget which is so compact in itself that provide an advantage of personal security system. This device will probably be very useful for the women. It is certainly a short term and preventive solution. This will be-proved as a multi-pronged strategy with the participation of multi stake holders of society. The creation of a hardware and software prototype has achieved two objectives: validation of the architecture and checking whether the utilized technology is Appropriate for the system. This system will help its users in difficult situation. This system would be highly sensitive and easy to handle. Its quick action response will help to send the information to the respective family members and police station. 


\section{International Journal of Engineering Applied Sciences and Technology, 2020 Vol. 4, Issue 11, ISSN No. 2455-2143, Pages 359-365 \\ Published Online March 2020 in IJEAST (http://www.ijeast.com)}

\section{FUTURE WORK}

In future system, a wireless band is provided for her in order to self defend herself, while this kit is carrying in his hand bag with the protected layers so an ON/OFF button is presented on the band so during the insecure time she used to $\mathrm{ON}$ the band so the location can be send to respective family members \& nearby police station.

\section{ACKNOWLEDGEMENT}

We are grateful to Mr. J. MAHESHKUMAR, Assistant Professor (E.C.E),for having allowed carrying out this paper work. we take this opportunity to express my profound and whole heartful thanks to our guide, who with his patience support and sincere guidance helped us in the successful completion of the paper.

We would like to thank MR. VENKATARAO, Professor and Head of Department (ECE), for valuable suggestions throughout our paper which have helped in giving define shape to this work. We are particularly indebted to him for his innovative ideas, valuable suggestions and guidance during the entire period of work and without his unfathomable energy and enthusiasm, this paper would not have been completed.

We like to express my deep sense of gratitude to Dr.

Sharma, Principal of GODAVARI INSTITUTE OF ENGINEERING AND TECHNOLOGY(A), for providing us a chance to undergo this paper in a prestigious institute.

\section{REFERENCES}

1. Nishant bahrdawaj and Nitish Agarwal, "Design and development of SURAKSHA"A women safety device" International journal of information \& computation technology,ISSN 0974-2239 volume4, number8(2014),pp. 787-792.

2. "Poonam Bhilarel, Swapnil Mankode4 and Rasika Khanae, "WOMEN EMPLOYEE SECURITY SYTEM USING GPS AND GSM BASED ON VECHILE TRACKING”, International journal for research in emergency science and technology, volume 2,issue-1,January-2015.

3. S,.K., Mukherjee .T. and Venkata subramaniam .K.K, "Body Area Networks : Safety, Security, and Sustainability," Cambridge University Press,2013.
4. Manisha Mohan , B-Tech., Automobile Engineering(2015).,"TECHONOLOGICAL INTERVENTIONS TO DETECT, COMMUNICATE AND PREVENT SEXUAL ASSAULT.”, Massachusetts Institute of Technology.

5. J. Mahesh kumar J.Haneesh Kumar, J.Siva ,Y.Mangamma, and N. Pooja "Real Time Patient Health Monitoring System Using IoT,2017/4,IJMETMR, Vol 4,Issue 4,Pp 215221. 